\title{
PEDAGOGICAL REQUIREMENTS FOR THE IMPLEMENTATION OF DIFFERENTIATED APPROACH IN TEACHING ELEMENTARY SCHOOL CHILDREN
}

\author{
Gulnara Faridovna Dulmukhametova ${ }^{1}$, Zarina Nailevna Sirazieva ${ }^{2}$, Gulnara Faritovna Gali ${ }^{3}$, \\ Usova Svetlana Nicolaevna ${ }^{4}$, Dilbar Valievna Shamsutdinova ${ }^{5}$ \\ ${ }^{1,3,4}$ Candidate of pedagogical sciences, ${ }^{2}$ Candidate of philological sciences, ${ }^{5}$ Doctor of Education \\ ${ }^{1}$ Kazan Innovation University, Kazan, Russia, ${ }^{2,3}$ Kazan Federal University, Kazan, Russia \\ ${ }^{4}$ Academy of Social Education, Moscow, Russia, ${ }^{5}$ Kazan State University of Culture and Arts, Kazan, Russia. \\ Email: dulmuhametova.gulnara@yandex.ru
}

Article History: Received on $15^{\text {th }}$ July 2019, Revised on $30^{\text {th }}$ August 2019, Published on $18^{\text {th }}$ September 2019

\begin{abstract}
Purpose of the Study: The article describes the authors' view on the model of the implementation of a differentiated approach in the training of elementary school children.
\end{abstract}

\begin{abstract}
Methodology: In the research, the authors identify and systematize the pedagogical requirements for ensuring the sex differentiation in education of elementary school children, together forming a meaningful model for implementing a gender approach to the educational process of primary school and including gender education for students, teachers, and parents. The authors analyze the category of sex differentiation in domestic and foreign pedagogy.
\end{abstract}

Result: The authors theoretically describe the problem of implementing a differentiated approach in teaching elementary school children, and also substantiate the experimental work on testing the effectiveness of pedagogical conditions that interconnect and complement each other, forming a dynamic system that ensures the effective organization of the sex differentiation of elementary school children.

Application and Novelty: Presented pedagogical requirements and model of a gender approach to the educational process can solve the age and gender problems of elementary school children and harmonize their relationships. Data of the article can be used not only in the educational process of elementary school, but also at the lessons of such subjects as "Pedagogical psychology", "Developmental psychology", and "Differential psychology" at the university. These requirements give the opportunity to prepare more qualified and competent psychologists and teachers for elementary school.

\section{Keywords: Education, Pedagogical Conditions, Differentiated Approach, School Children.}

\section{INTRODUCTION}

The main direction of modern school modernization is to beconnected with the idea of creating conditions for the development of personality and disclosure of student's individuality, its self-realization in life. The theorists and practitioners are faced with the task of improving the teaching of schoolchildren as the leading type of activity, identifying the conditions for improving the quality of education, among which differentiation of instruction is of no small importance.

The interest in the problem of differentiation of education is not so much due to the fact that the category of sex is a complex psychological, historical, cultural, and social problem, as the fact that modern requirements for upbringing an individual approach to the formation of personality cannot be realized without taking into account the psychological specifics of the sex of a child.

The scientific formulation of the problem of differentiation of school children's education is due to the urgent need to update the education system. First of all, it concerns the trend of humanization of the educational process that has been gaining strength in recent years. The world pedagogical community has declared humanism as a fundamental principle of social progress and the development of education.

In addition to the psychophysiological basis of the distinctive features of boys and girls, there is a social aspect of the development of the child's personality, i.e. socially determined ideas about a man and a woman, their place, and role in society. These ideas have a great influence on the gender culture of the child. It is necessary that the process of training and education of students was comfortable psychologically and contributed to their personal development. In 2004, the Gender Strategy of the Russian Federation was adopted, which actualizes the importance of developing gender-oriented programs in the process of modernizing Russian education. In the Russian educational practice, there are several attempts 
to solve the problem of taking into account the age and gender characteristics of students (the creation, along with the traditional classes with separate training, and the organization of the half-differentiated teaching of certain academic subjects).

In real educational practice, the teacher is guided by a certain average student without taking into account his psychophysiological features. Under the conditions of a heterogeneous class, gender and age characteristics of children are not taken into account. Model programs and strategies for the implementation of these programs by teachers do not meet the logic and psychophysiological characteristics of the development of cognitive processes of students of different sexes. This was reflected already in the early school years. The younger school age is a period of gender segregation, when children try to avoid members of the other sex. This leads to the fact that children do not know how to communicate with members of the opposite sex, which causes certain problems in adolescence. The younger school age is characterized by susceptibility to external influences, compliant with the emotional impact and therefore is sensitive tothe formation of psychological gender identity and optimization of relationships with representatives of the opposite gender.

A review of the scientific literature has shown that in pedagogical science, there is a fairly large amount of research on the problems of sex education (Andreev, 2008; Isaev, 2004). In the psychological-pedagogical literature, there are various aspects of gender approach in pedagogy (Bulatova, Korobkova, Kostikova, Nadolinskaya, Nikitina, Rykov, Sabunaeva, Simonov) (Bulatova, 2009; Korobkova, 2005); there are works on the problem of gender differences among students (Breslov, Buzhigeeva, Kon, Mudrik, Hasan) (Breslov, 1990). The theoretical analysis of the problems of gender in psychology is devoted to the work of I.S. Kletsinoy. Gender issues in education and gender socialization are highlighted by Guseva (Guseva, 2001), Kostikova, Popova, Radzina, Tsareva. Theses on the problems of gender and gender role approaches in education are of particular importance for our study (Konstantinova (Konstantinova, 2005), Rozhkova, Tatarintseva). Formation of gender aspects in Russian society was studied by Abubikirova; The study of women's gender in history carried out by Pushkarev (Fakhrutdinova, Fakhrutdinova \& Severyanov, 2013). Consideration of gender differences in preschool children in the educational process in the formation of children's intellectual readiness for schooling is highlighted by Tereshchenko (Tereshchenko, 2007); in the formation of physical culture - Matveyeva (Matveeva, 2007). The issues of interaction between teachers and older teens in the educational process, taking into account sexual differentiation were studied by Antipov; on the subjects of the natural science cycle - Korobkova (Korobkova, 2005); when teaching Chemistry - Kornilaev (Mefodeva, Fakhrutdinova \& Zakirova, 2016) and History Solovyov. The gender features of teaching foreign language to children of primary school age when teaching English were revealed by Petrova; humanizing potential of gender-oriented German language classes - Saharchuk (2005). For all the significance of the research performed, the methodological foundations and the organizational and pedagogical conditions for the differentiation of the education of elementary school children remain insufficiently developed. Noting the undoubted value of the developed fundamental provisions on the general pedagogical problems of a differentiated approach to learning and its basic characteristics, it should be recognized that at the present stage, the accumulated experience and theoretical approaches to the differentiation of elementary school children require careful analysis.

\section{METHODS}

The objects of our investigation are: 1) theoretically substantiate and experimentally verify pedagogical support of sex differentiation of the education of elementary school children in the practice of a comprehensive school, 2) to reveal the essence, content, and main characteristics of the concept of "sex differentiation " in the context of psychological and pedagogical research, 3) to determine and experimentally check the complex of pedagogical conditions of sex differentiation of elementary school children.

For confirmation of the hypothesis we need to turn to a variety of methods, such astheoretical analysis and synthesis; the study of philosophical, psychological, educational, methodical literature, and documents of educational institutions; studying of program and regulatory documents; generalization of advanced pedagogical experience; interrogativediagnostic methods (interrogation, observation, questioning, conversation, and interviewing); practical methods (study of products of activity and study of school documentation); pedagogical experiment, including ascertaining, formative, and control stages; methods of statistical information processing.

The fundamental works of foreign and Russian scientists in the field of pedagogy and psychology of elementary school children (Amonashvili, Ananiev, Bozhovich, Vygotsky, Vinogradova, Dubrovina, Zimnyaya, Leontiev, Podlasyy, Slastenin, Savchenko) were the theoretical basis of the research (Gulnara, 2018; Combs, 2009). The usage of the methodology and methods of existing research contributes to the development of scientific thought in education for 
elementary school children. It provides the opportunity to comprehensively solve the problem of teaching elementary school children with a differentiated approach.

\section{RESULTS}

The pedagogical support of differentiated approach of teaching elementary schoolchildren allowed us to get certain results in the personal and cognitive development of students' interest in learning results and heightened cognitive interest significantly increased in experimental groups of both, boys and girls; more stable interpersonal relations and mutual responsibility were established between children in the experimental classes; boys and girls became closer (in the control classes, friendships are more often based on the principle: "with whom I sit, with whom I live next to"; boys prefer to be friends with boys, and girls - with girls); the high masculinity of girls decreased significantly in the experimental classes, while this indicator increased markedly among boys in these classes; the levels of formation of masculinity qualities in boys and femininity in girls in the control groups changed positively, but only slightly; the level of formation of gender culture among the subjects of experimental group increased significantly; the majority of children in the control groups had low and medium levels of formation of gender culture.

The results of this survey show a positive trend in the levels of effectiveness of differentiation of elementary school children, while respecting the complex pedagogical conditions: the organization of the educational process in elementary school, taking into account the age and gender characteristics of students and the half-differentiated attitude to learning; to equip teachers with modern social and humanitarian knowledge about the differentiation of education, its structure, characteristics, and quality indicators at various stages of the organization of the educational process; the formation of a gender culture of elementary school children, the most important component of which is conscious positive gender behavior that corresponds to the biological sex and is based on respect; recognition of the dignity of both sexes and the uniqueness of the male-female identity as a subject of relationships; the interaction of school and family to develop the psychological and practical readiness of parents to solve the age and gender problems of elementary school children and to harmonize the relationship of the sexes through the formation of a culture of their relationship.

According to the results of diagnostics, there is observed a dynamics of indicators for each criterion of efficiency (motivational, activity, and effective). With a set of specified pedagogical conditions, the effective implementation of differentiation of education of elementary school children is possible.

\section{Main findings of the study}

1. Analysis of philosophical, psychological, and pedagogical literature allows us to conclude that in modern Russian society, the problem of differentiation of education is of particular relevance due to the urgent need to update the education system.

2. In the Russian society, there is a contradiction of views on the separation of boys and girls from the moment of its appearance to the present, while in the west, it has a strong pedagogical tradition.

3. Sexual differentiation of education in modern conditions is understood as a form of organization of the educational process in which students group in a lesson based on the psychophysiological characteristics of boys and girls to perform tasks in different ways, taking into account the goals and objectives of training.

4. The pedagogical conditions of the effectiveness of differentiation of education, ensuring the effectiveness of learning process, taking into account the characteristics of younger school children are: the organization of educational process in elementary school, taking into account the age and gender characteristics of students and the half-differentiated attitude to learning; to equip teachers with modern social and humanitarian knowledge about the differentiation of education, its structure, characteristics, and quality indicators at various stages of the organization of the educational process; the formation of a gender culture of elementary school children, the most important component of which is a conscious positive gender behavior that corresponds to the biological sex and is based on respect; recognition of the dignity of both sexes and the uniqueness of the male / female individuality as a subject of relationships; interaction of school and family to develop the psychological and practical readiness of parents to solve the age and gender problems of elementary school children and to harmonize gender relations based on the formation of a culture of their relationship.

The study confirmed the main provisions of the hypothesis, however, they do not exhaust all the issues related to the study of the effectiveness of the process of differentiation of education of elementary school children.

In the course of the study and understanding of its results, new tasks were outlined, the solution of which is fundamentally important: further search and specification of signs and indicators by which the effectiveness of activities 
of teachers and students in the framework of differentiation of education should be assessed; scientific-theoretical and organizational-methodological support of the process of preparing teachers for the implementation of differentiation of education in the educational space of school (in the system of advanced training of educators).

\section{DISCUSSION}

The basic reason to make a detailed analysis of differentiated education of elementary school children is the pedagogical conditions. The research has shown that the problem is considered as one of the most important in the world. Of course, the special teacher training, i.e., professional and personal qualifications of teachers contribute to the effective solution of the problem of the implementation of a differentiated approach in teaching elementary school children.

Various aspects of the problem of sex education are reflected in the scientific work of researchers such as Kagan, Khripkov; trends in the development of gender differentiation of education in educational institutions of the Republic of Tatarstan (1985-2000) are revealed in the study of Sheymardanova; gender-based education of teachers and their preparation for the implementation of a gender approach in education are revealed in the works of Rosova, Shtyleva, Shustova, Yarskoy-Smirnova. However, analysis of scientific papers on this issue showed us that this problem is not sufficiently considered.

\section{SUMMARY}

In our study, pedagogical conditions for the implementation of differentiated approach in teaching elementary school children was developed. It had the following structure: the organization of educational process in elementary school, taking into account the gender-racial characteristics of students and a semi-differentiated attitude to learning; to equip teachers with modern social and humanitarian knowledge about the sexual differentiation of education, its structure, characteristics, and quality indicators at various stages of the organization of the educational process; the formation of a gender culture of younger school children, the most important component of which is a conscious positive gender behavior appropriate to the biological sex and based on respect; recognition of the dignity of both sexes and the uniqueness of the male / female individuality as a subject of relationships; the interaction of school and family to develop the psychological and practical readiness of parents to solve the age and gender problems of elementary school children and to harmonize the relationship of the sexes through the formation of a culture of their relationship.

\section{CONCLUSIONS}

The research has revealed that with a set of specified pedagogical conditions, the effective implementation of a differentiated approach of education of elementary school children is possible and effective.

In the course of the study and understanding of its results, new tasks were outlined, the solution of which is fundamentally important: 1) further search and specification of signs and indicators by which to evaluate the effectiveness of teachers and students in the framework of differentiated approach of education; 2) scientific and theoretical, organizational and methodological support of the process of preparing teachers for the implementation of differentiated approach of education in the educational space of school (in the system of advanced training of education workers).

\section{ACKNOWLEDGEMENT}

The work is performed according to the Russian Government Program of Competitive Growth of Kazan Federal University.

\section{REFERENCES}

1. Andreev V.I. (2008). Pedagogy of creative self-development. Innovation course. Book 2. - Kazan University Press, 233 p. Retrieved from https://www.medwelljournals.com/ref.php?doi=sscience.2015.449.453

2. Isaev D.N. (2004). Sexual education of children: Medical and psychological aspects / D.N. Isaev, V.E.Kagan. 2nd ed. - L.: Medicina, $160 \mathrm{p}$.

3. Bulatova L.A. (2009). Gender aspects of teaching in high school / L.A. Bulatova // Proceedings of the 2nd international interdisciplinary scientific-practical conference. Minsk, pp. 111-117. Retrieved from https://www.researchgate.net/publication/320864184_Hygienic_aspects_of_physical_education_and_health_of_s choolchildren

4. Korobkova S.A. (2005). Formation of the relationship between the teacher and the teenager, taking into account sexual characteristics (on the examples of the natural science cycle): Dis ... Candidate of Pedagogics [Text] / S.A. Korobkova. - Volgograd, $174 \mathrm{p}$. 
5. Breslov G.M. (1990). Gender differences and modern school education / G.M. Breslov, B.I. Hassan // Questions of psychology. №3, pp. 64-69. Retrieved from https://en.wikipedia.org/wiki/Breslov_(Hasidic_group)

6. Guseva Yu.E. (2001). Gender Conceptions as a Socio-Cultural Phenomene Russian Women and European Culture: Proceedings of the V Conference devoted to the theory and history of the women's movement. St. Petersburg: Publishing House of the St. Petersburg Philosophical Society, pp. 235 - 238.

7. Konstantinova O.A. (2005). Gender approach to school education: Dis ... Candidate of Pedagogics [Text] / O.A. Konstantinov. - Saratov, 174 p.

8. Fakhrutdinova E., Fakhrutdinova A., Severyanov O. (2013). The transformation of educational approaches at the time of social and economical changes//World Applied Sciences Journal. Vol.27, Is.13, pp. 15-19.

9. Tereshchenko M.N. (2007). Formation of intellectual readiness of children to study at school, taking into account their gender characteristics. Dis ... Kand.ped.nauk. [Text]. / M.N. Tereshchenko. - Chelyabinsk, 165 p. Retrieved from http://sociosphera.com/files/conference/2016/k-04_18_16.pdf

10. Matveeva A.V. (2007). Formation of the physical culture of the personality of the children of senior preschool age, taking into account their sex differences: Dis ... kan.ped.nauk [Text] / A.B. Matveyev. - St. Petersburg, 250 p.

11. Korobkova S.A. (2005). Formation of the relationship between the teacher and the teenager, taking into account sexual characteristics (on the examples of the natural science cycle): Dis ... Candidate of Pedagogics [Text] / S.A. Korobkova. - Volgograd, $174 \mathrm{p}$.

12. Mefodeva, M.A., Fakhrutdinova, A.V., Zakirova, R.R. (2016). Moral education in Russia and India: A comparative analysis Social Sciences, 11(15) pp.3765-3769.

13. Sakharchuk E.S. (2005). The humanizing potential of gender-oriented activities. On the example of teaching German in high school: Dis ... Candidate of Pedagogics [Text] / E.S. Saharchuk. - Moscow, 188 p.

14. Gali G. (2018). The Specificity of Gifted Students' Teaching: Overseas Data / Gulnara Gali, Irina Shakhnina, Elena Zagladina, Evguenia Belyaeva, Gulnara Dulmukhametova, Anfisa Ibragimova // Proceedings of INTCESS 2018- 5th International Conference on Education and Social Sciences 5-7 February 2018- Istanbul, Turkey.-p.2531.

15. Combs A. (2009). The professional education of teachers: A perceptual view of teacher preparation, Boston: Allyn \& Bacon. Retrieved from http://revistas.proeditio.com/iush/quid/article/view/1786 